\title{
Seat Capacity Selection for an Advanced Short-Haul Aircraft Design
}

\author{
Ty V. Marien* \\ NASA Langley Research Center, Hampton, VA, 23681
}

\begin{abstract}
A study was performed to determine the target seat capacity for a proposed advanced short-haul aircraft concept projected to enter the fleet by 2030. This analysis projected the potential demand in the U.S. for a short-haul aircraft using a transportation theory approach, rather than selecting a target seat capacity based on recent industry trends or current market demand. A transportation systems model was used to create a point-to-point network of short-haul trips and then predict the number of annual origin-destination trips on this network. Aircraft of varying seat capacities were used to meet the demand on this network, assuming a single aircraft type for the entire short-haul fleet. For each aircraft size, the ticket revenue and operational costs were used to calculate a total market profitability metric for all feasible flights. The different aircraft sizes were compared, based on this market profitability metric and also the total number of annual round trips and markets served. Sensitivity studies were also performed to determine the effect of changing the aircraft cruise speed and maximum trip length. Using this analysis, the advanced short-haul aircraft design team was able to select a target seat capacity for their design.
\end{abstract}

\section{Introduction}

$\mathrm{T}$

HIS study was part of a NASA effort to develop a conceptual aircraft design capable of revitalizing the market for small short-haul aircraft that operate primarily out of regional and community airports. The Short-Haul Revitalization Study is exploring the incorporation of advanced airframe and propulsion technologies into an advanced small transport aircraft concept with the objective of increasing small transport safety, affordability, environmental compatibility, and customer acceptance. A very early step in the process was to determine the seat capacity of interest for this NASA conceptual aircraft study. For the aircraft designer, the seat capacity for a new design is normally a requirement developed by analysis of customer needs or market gaps. This requirement can be based on a specific need for an operator, a forecast based on market analysis or historic trends, or simply a best guess based on engineering judgment. In the case of the Short-Haul Revitalization Study, no seat capacity was given, and no market analysis had been performed for the proposed aircraft.

This paper presents a preliminary demand and market analysis for an advanced short-haul aircraft, with the goal of determining a target seat capacity. The analysis of the projected demand, operational cost, and ticket revenue of a future short-haul commercial aircraft was performed for several seat capacities to compare their potential profitability for a notional airline. This analysis was used by the study team, along with other design and operational factors, to determine the target seat capacity for the advanced short-haul vehicle. In addition, sensitivity analyses were performed for maximum trip length and cruise speed, once the target seat capacity was selected.

\section{Background}

During the 1990's, the commercial aviation industry experienced a significant market growth in the National Airspace System (NAS), especially in the short-haul sector. The sudden increase in direct-to routes was the result of a number of factors. Fuel costs, economic conditions, and aggressive airline market share strategies were all important ingredients in creating the environment where this growth in connectivity could occur ${ }^{1}$. From a technology perspective, an important factor was the introduction of the regional jet. The Bombardier CRJ and Embraer ERJ regional jets represented an advance in technology that allowed these aircraft to be economical enough to compete with turboprop aircraft on many short-haul routes. In addition, these 50 seat regional jets had much

*Aerospace Engineer, Aeronautics Systems Analysis Branch, MS 442.

1

American Institute of Aeronautics and Astronautics 
better passenger acceptance than the turboprops they began displacing. Airlines used these aircraft to create new markets between regional airports, increasing passenger choice and reducing passenger travel times.

The last decade has seen a significant decline in many short-haul markets. There have been a number of contributing factors, including increased fuel prices, the recession, higher fares, airport delays, and new technology for business meetings ${ }^{2}{ }^{3}$. Many of the smaller markets are no longer economical, and airlines have either reduced or eliminated service. Airlines have begun retiring their fleet of 50 seat regional jets in favor of larger aircraft with better cost per seat-mile and higher customer acceptance ${ }^{3}$. The focus has shifted from capturing market share to consolidating operations in the most profitable routes. Airlines have also increased the average load factor for flights, resulting in fewer daily flights on some routes. This new airline operations paradigm has contributed to the significant loss of connectivity for many regional airports ${ }^{4}$.

NASA recently initiated a small study to develop a conceptual design for a small advanced short-haul aircraft. The goal of this Short-Haul Revitalization Study is to investigate the potential for a new aircraft type to reverse the current trend in the short-haul segment, through either application of advanced technology or advanced flight operations. If a small short-haul aircraft could be operated economically compared to larger aircraft, it could potentially encourage airlines to open up new markets, reestablish service at smaller airports, and increase mobility and connectivity for passengers.

An initial study assumption was that a small (less than 50 passenger) aircraft was needed to provide the desired mobility potential associated with revitalizing short-haul air transportation. A small aircraft should open up more routes with the ability to operate in markets where demand is low. However, there was no analysis behind this assumption other than the fact that commercial service has delined the most for markets employing smaller aircraft ${ }^{4}$. Furthermore, no analysis had been done to determine the potential markets and aircraft passenger capacities needed for an airline to operate profitably. Therefore, an effort was launched to perform a relatively quick analysis of potential market demand for short-haul aircraft of different passenger capacities. This analysis would help the design team select a target seat capacity and continue with the requirements development of the concept.

\section{Technical Approach}

The design team made some initial assumptions that served as ground rules for this analysis. The year 2030 was chosen as the target for introduction of the advanced short-haul aircraft into the fleet. The aircraft would notionally be a turboprop and would travel at cruise speeds consistent with current turboprop aircraft. A turbofan-powered advanced short-haul aircraft will also be considered by the team; however, it was determined that the flight speeds associated with a turboprop was a good initial assumption for this analysis. The maximum range for this aircraft would be $900 \mathrm{NM}$. The field length requirement for the aircraft would be $4,000 \mathrm{ft}$.

The approach for determining the target seat capacity was to predict the potential markets for a series of advanced short-haul aircraft of varying passenger capacities, and then compare the results. Both passenger demand and airline profitability were considered in the analysis. The first step was to determine the short-haul markets where passengers would like to fly if they were available. The important consideration in this step is the passenger choice to fly on that route or select another travel mode, based on the airfare and travel time. The second step was to determine which of these potential short-haul markets an airline might want to operate in, by comparing the costs of operating in that market versus the potential passenger revenue of that market. This same analysis was repeated for a number of aircraft capacities between 20 and 80 passengers, and the results were compared. The metrics used to determine the target passenger capacity were airline profitability in the short-haul markets, the total number of annual trips serviced by the short-haul markets, and the total number of short-haul markets served.

An airline's decision to operate a particular aircraft size or type in a given market is influenced by a number of factors. The desired load factor, cost per seat-mile, number of daily operations, operating costs, crew and aircraft scheduling, and a host of other factors all weigh in this decision. Also, competition between airlines is a major factor that can affect air fares and services offered in a given market. Determining the behavior of different airlines based on their economics and competition strategies is beyond the scope of this study. Instead, a single airline is assumed to operate the advanced short-haul aircraft and compete with the regular commercial service in all feasible shorthaul markets. This notional airline would use a point-to-point operations model, and operate only one aircraft type over all the short-haul routes in its network. The complex nature of the hub-and-spoke network and the difficulties of integrating that network into the regular commercial airline network put that type of analysis beyond the reach of this quick-look study. A more complete analysis that considers a hub-and-spoke operations network is planned for the future.

\section{A. Transportation Systems Analysis Model}


The Transportation Systems Analysis Model (TSAM) was used to determine the passenger demand for shorthaul flights in the U.S. TSAM was developed by Virginia Tech's Air Transportation Laboratory and NASA's Langley Research Center. It uses socio-economic and demographic data to forecast intercity travel behavior in the contiguous United States out to the year $2040^{5}$. TSAM allows for different modes of travel (e.g. commercial air, automobile, and rail). It also supports any new mode of travel that the user can model with performance and cost data.

A four-step process taken from classic transportation theory is used to forecast air traffic demand:

1) Trip Generation

2) Trip Distribution

3) Mode Choice

4) Network Assignment

TSAM uses the Woods and Poole database of socio-economic and demographic data ${ }^{6}$, which forecasts the population income levels and employment factors for each county in the contiguous U.S. out to 2050. Data from the American Travel Survey (ATS $)^{7}$ is also used, which allows TSAM to infer how many annual personal and business trips the residents of each county will take based on their income level. The Trip Generation step forecasts the number of trips generated-by and attracted-to each county. In the Trip Distribution step, TSAM connects the generated trips in each county to the attracted trips in other counties, using a distribution algorithm based on a gravity-type model. In the Mode Choice step, each trip is run through a utility function to determine which travel mode (auto, commercial air, etc.) the trip will use, based primarily on the mode cost and travel time. In the Network Assignment step, the air traffic trips are given origin and destination airports, and assigned routes on the network from origin to destination.

For this study, the advanced short-haul aircraft was modeled as its own independent travel mode, which competes for trips with the other modes. This means that the short-haul mode consists solely of the flights utilizing the advanced short-haul aircraft. These flights would compete directly against commercial air short-haul aircraft (e.g. single aisle jets, regional jets, turboprops, etc.), and also automobiles for trips between origin-destination (O-D) city pairs of less than $900 \mathrm{NM}$. As previously mentioned, the short-haul mode utilizes a direct point-to-point network between the O-D pairs, whereas the commercial air mode uses the existing hub-and-spoke network. The advanced short-haul aircraft was assumed to be able to operate out of all current commercial airports with at least one paved runway of 4,000 ft. or longer. Short-haul flights were not allowed to make multiple hops between O-D pairs.

The TSAM Mode Choice step was used to determine how many passengers chose to travel via the short-haul mode versus automobile and regular commercial air modes. In order to calculate the passenger utility for the Mode Choice step, it was necessary to develop airfare models and travel time profiles for the short-haul travel mode. A speed profile (average ground speed vs. great circle distance) was developed for a representative turboprop aircraft, which TSAM used to determine the travel time for each short-haul trip. Short-haul trip fares were calculated using fare profiles for both business and non-business trips, using a method from Rama-Murthy ${ }^{8}$. This fare model predicts airfares based on great circle distance between airports.

\section{B. TSAM Output Post-Processing and Analysis}

The TSAM Trip Generation, Trip Distribution, and Mode Choice steps were run for the year 2030, with the short-haul mode competing with commercial air and automobile for trips between O-D pairs. Once the Mode Choice step had determined the number of overall trips that were captured by the short-haul mode, trip tables were generated. These tables contained all business and non-business short-haul trips for each O-D pair for the year 2030.

The TSAM output tables contain the potential short-haul O-D pairs for the advanced short-haul aircraft, based on passenger demand in those markets. A fare structure was assumed for all of these markets, but no consideration was given in the TSAM analysis to the airline operational costs in each market. Also, a large number of these markets have too little demand for an airline to bother operating in that market. A filtering procedure was needed to remove markets that an airline would not want to operate in due to profitability and/or operational reasons.

An O-D Market Profitability Metric (MPM) was created to help determine the most profitable short-haul markets. This metric consisted of the short-haul trip revenue, as determined by the short-haul fare model, minus the short-haul trip operating cost to the airline. Trip costs were calculated using a method described by Swan and Adler ${ }^{9}$ for short-haul flights. This method assumes trip cost is linear with trip distance and seat capacity. The operating cost includes pilot, cabin crew, fuel, airframe maintenance, engine maintenance, and ownership costs. It does not include any of the airline's other fixed costs.

For each O-D pair, business and non-business round trips were aggregated into daily flights, based on an assumed seat capacity value. The MPM was calculated for the day's flights, subtracting the total trip costs for each 
flight from the total fares. O-D pairs where the MPM was negative (the total flight costs exceeded the total fare revenues) were filtered out, with the assumption that an airline would not choose to operate in an unprofitable market. In addition, the TSAM trip table outputs were filtered by setting limits on the minimum and maximum number of daily flights between O-D pairs. If there were only fractional daily round trip flights between an O-D pair, then that O-D pair was excluded from the analysis. The assumption is that an airline would not choose to operate in a market with less than one round trip flight per day. Conversely, if an O-D pair had more than five round trip flights per day, then it was assumed that an airline would choose to operate a larger aircraft for that market and that O-D pair was excluded from the analysis. Finally, the trip tables were filtered to insure that all the O-D pair distances were under the advanced short-haul aircraft maximum design range (900 NM).

After all the filtering was completed, the total daily operations, costs, and fare revenues across all of the feasible O-D pairs was aggregated. These aggregated results represented the values for a single aircraft seat capacity. The analysis was repeated for each aircraft seat capacity.

\section{Results and Discussion}

The above analysis was performed using the short-haul aircraft seat capacity as the independent variable, with the hopes that a trend could be identified or an optimum value found for one of the metrics of interest. Fortunately, an optimum value was present for the MPM, as seen in Fig. 1. As the short-haul aircraft seat capacity increases from 20 seats to 80 seats, the MPM increases and reaches a maximum at approximately 70 seats. With respect to the MPM, this represents the best seat capacity for a single aircraft type operating in all profitable markets shorter than $900 \mathrm{NM}$, using a point-to-point operational model with current technology.

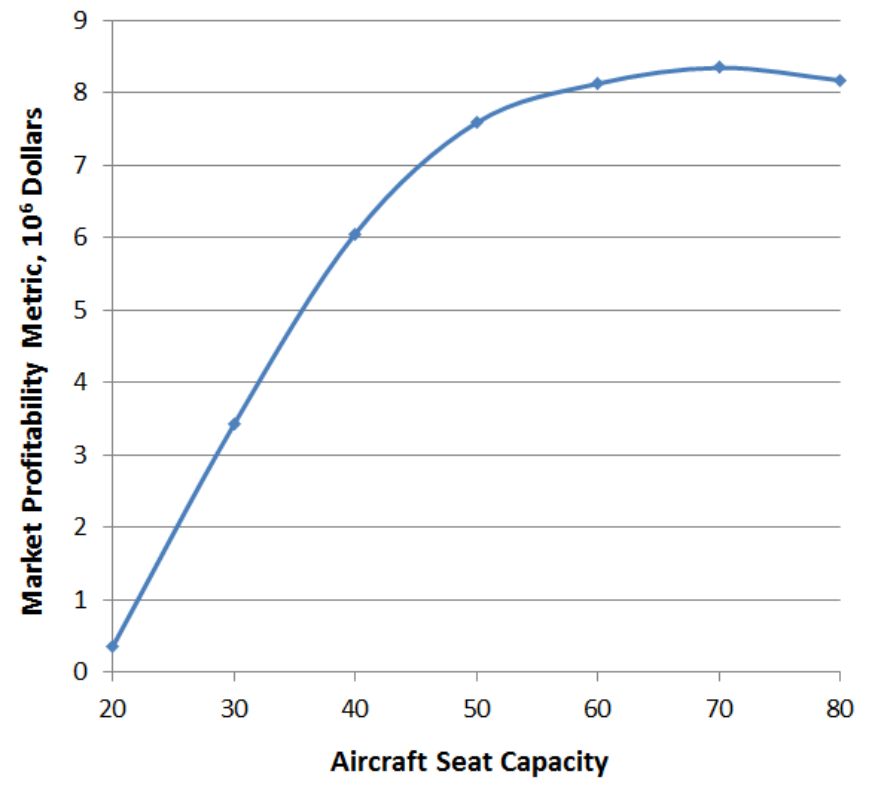

Figure 1. Market Profitability Metric vs. Aircraft Seat Capacity.

\section{A. Effect of Operating Cost Reductions}

The Short-Haul Revitalization Study will be focusing on ways to reduce the operating cost for the advanced short-haul aircraft. The next step in the analysis was to determine if the maximum MPM shifts when the aircraft operating costs for the new aircraft type are significantly lower than the baseline. Figure 2 shows the relationship between aircraft seat capacity and operating cost, in terms of dollars per available seat-mile (ASM), using the Swan and Adler method for a trip distance of $900 \mathrm{NM}$. It shows the significant effect seat capacity has on operating cost, and how the curve begins to flatten out as seat capacities increase. Also shown is the effect of applying simple across-the-board cost reductions on the baseline cost curve. 


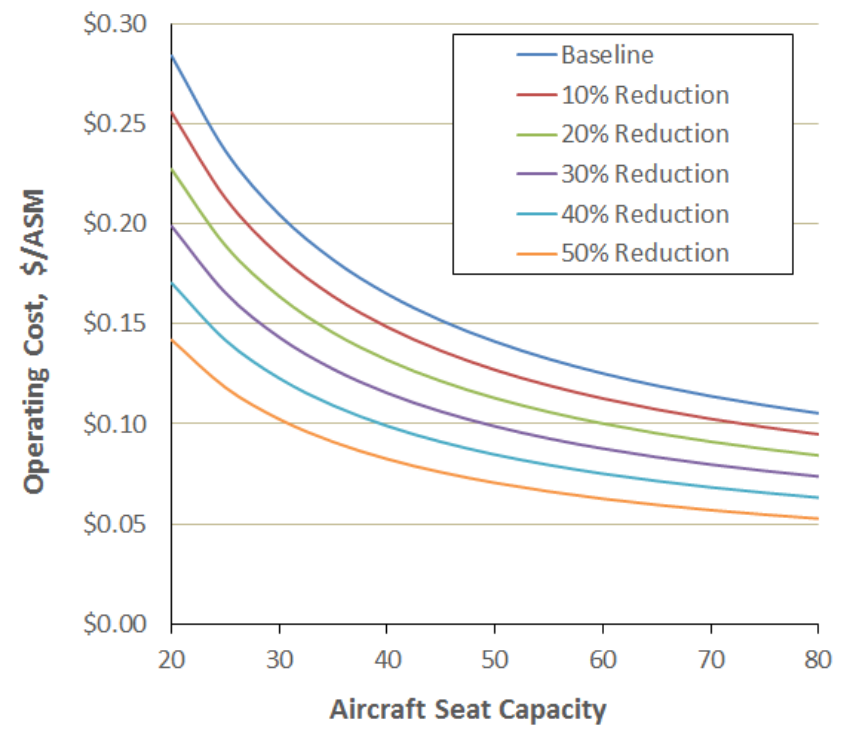

Figure 2. Operating Cost vs. Aircraft Seat Capacity.

Simple percentage reductions were applied to the trip costs in the previous analysis to determine if the optimum MPM would occur at a different seat capacity value. The results are shown in Fig. 3, with the original baseline curve also shown. The aircraft seat capacity with the highest MPM shifts towards smaller values with increasing cost improvements. If it were possible to reduce the operating cost by 50\%, the aircraft seat capacity with highest MPM would be about 35 passengers, compared to 70 for the baseline case. This effect is due to the smaller aircraft benefiting more from lower operating costs. As the operating costs go down, more O-D pairs become profitable. Recall that in this analysis, O-D pairs with a negative value for the airline profit metric are filtered out. As those markets become profitable with lower operating costs, they are included back in the analysis. Smaller aircraft benefit more than larger aircraft because it is easier to fill up a smaller aircraft and achieve the one round trip flight per day operational requirement for that O-D pair. Larger aircraft benefit from the cost reductions in the markets they already operate in, but see fewer new markets open up.

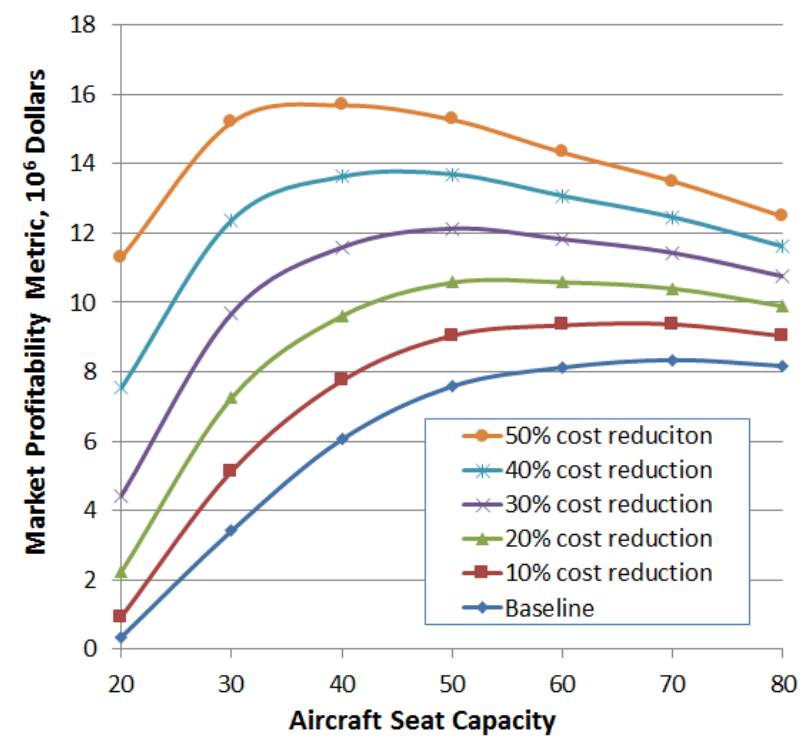

Figure 3. MPM vs. Seat Gapacity for different levels of GasteRedphtionete of Aeronautics and Astronautics 
Based strictly on the MPM, this analysis suggests that the target design seat capacity is somewhere between 50 and 70 passengers, assuming an operating cost reduction between 0 and 25 percent for the advanced short-haul aircraft. The Short-Haul Revitalization Study will try to answer the question of how much cost reduction is potentially possible by defining a set of advanced technologies and/or operational procedures, and determining the operating cost reduction realized.

\section{B. Mobility as a Factor}

Although airline profitability is an important consideration in determining the target seat capacity for the advanced short-haul aircraft, increased mobility for the flying public is an important goal for NASA. NASA's Aeronautics Research Mission Directorate has identified three overarching drivers to guide research planning in its Strategic Implementation Plan (SIP). The first "Mega-Driver" is "Global Growth in Demand for High Speed Mobility." " The analysis was therefore repeated using mobility metrics to determine the best aircraft seat capacity, instead of the MPM. Two metrics were chosen to represent mobility for passengers: number of annual round trips, and number of O-D pairs served.

\section{Number of Annual Round Trips}

The first metric used to represent mobility is the total number of annual round trips taken for the short-haul transportation mode. These trips represent person-trips, not aircraft flights. As previously described, the number of annual round trips is calculated for each O-D pair (after excluding the unprofitable markets, and markets outside the operational limits previously described). The results can be seen in Fig. 4. For the baseline case, the maximum number of annual round trips occurs with a seat capacity of approximately 44 passengers. As larger operational cost reductions are assumed, the maximum point in the curve shifts towards smaller seat capacities. This is the same effect seen for the MPM in Fig. 3. The same reasoning applies; the smaller aircraft benefit more than the larger aircraft because more new markets open up to smaller aircraft as operating cost is reduced.

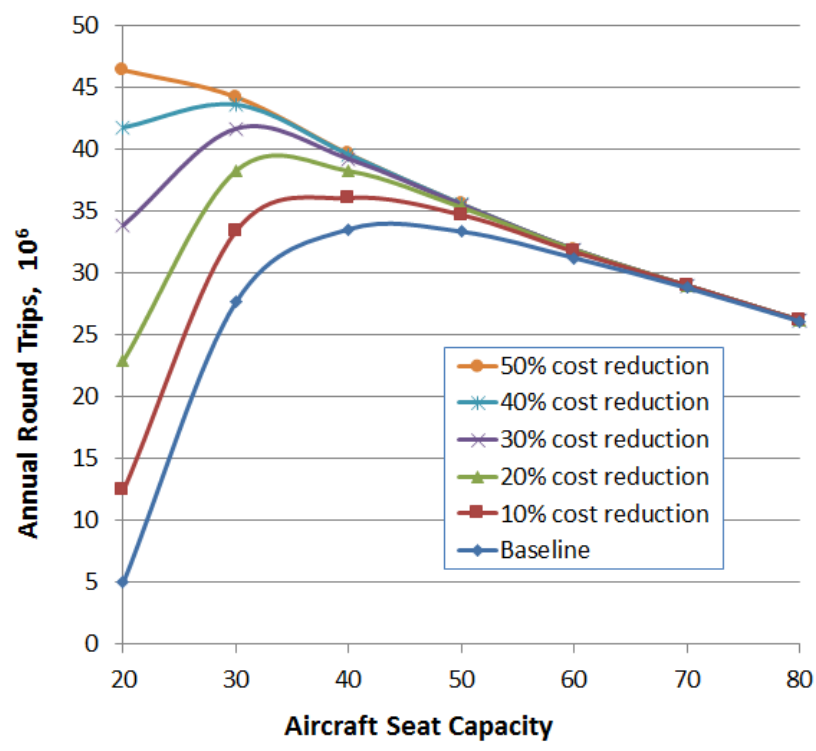

Figure 4. Number of Annual Round Trips vs. Seat Capacity for different levels of Trip Cost Reduction.

\section{Number of $O-D$ Pairs}

The second mobility metric examined in this analysis is the total number of O-D pairs served by the short-haul travel mode. More markets served implies more passenger choice and greater mobility. Figure 5 shows the number of short-haul O-D pairs vs. the aircraft seat capacity, for the baseline and the cost reduction cases. Using this metric, the best seat capacity for the baseline case is between 35 and 40 passengers, even lower than for the annual round 
trip metric. As seen with the other metrics, the best seat capacity shifts towards smaller values as operating costs are reduced. Aircraft larger than about 60 seats see little-to-no benefit in terms of markets served because they are too large to serve the thousands of thin markets that open up.

It is interesting to note that for cost reductions of $40 \%$ or more, the seat capacity with the maximum O-D pairs served is driven towards very small values, into the realm of general aviation or possibly personal air vehicles (PAVs). Perhaps one day very small fully automated aircraft may be feasible and operate economically enough to represent a mobility solution for the NAS.

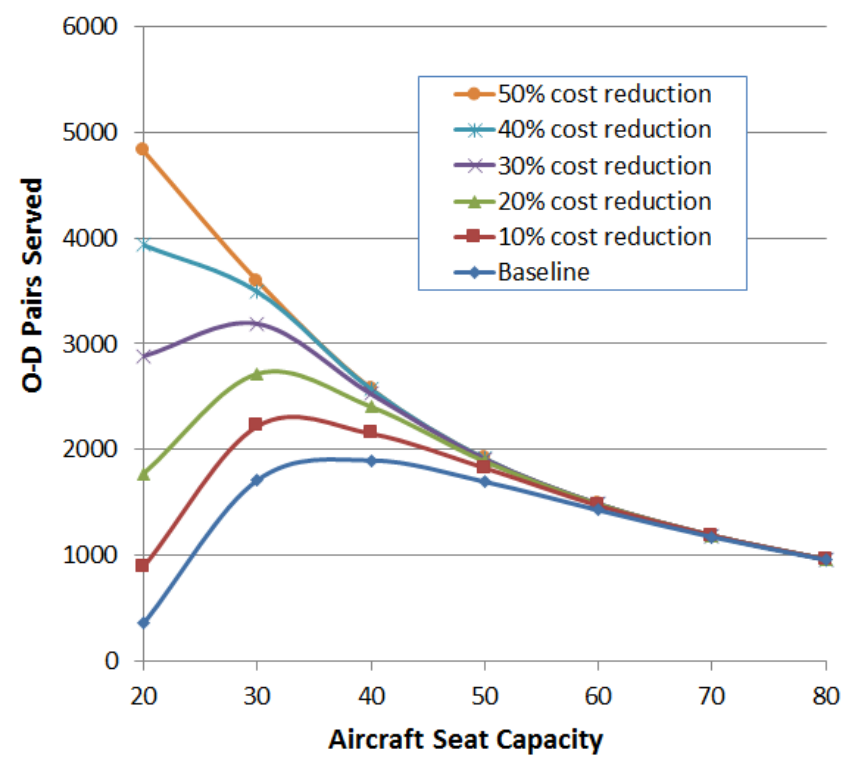

Figure 5. Number of Short-Haul O-D Pairs Served vs. Seat Capacity for different levels of Cost Reduction.

\section{Seat Capacity Selection}

The Short-Haul Revitalization Study design team was ultimately left with a range of aircraft seat capacities to consider. The team had to weigh the relative importance of airline profitability versus mobility for the public, and consider the possible reductions in operating cost for the advanced short-haul aircraft. There were also other considerations outside the scope of this analysis, such as the Federal Aviation Regulations (FAR) requirement for an additional flight attendant if the seat capacity is 50 or more. Ultimately, the design team chose a design seat capacity of 48 for the advanced short-haul aircraft. This aircraft size was a good compromise for achieving the study goals. Also, this seat capacity is the same as the ATR 42-600, which will allow a direct comparison of the advanced shorthaul aircraft to a current technology aircraft that performs a similar mission.

\section{Trip Length and Cruise Speed Sensitivities}

A sensitivity analysis was performed for cruise speed and maximum trip length, using a 48 passenger capacity for the advanced short-haul aircraft. The previous analysis assumed a maximum trip length of $900 \mathrm{NM}$, which matches the maximum design range requirement for the advanced short-haul aircraft. Routes requiring a stop for refueling were not allowed. The sensitivity analysis placed an upper limit on the trip length, from 300 NM to 900 NM, to determine the sensitivity of demand to maximum trip length. Cruise speeds were also varied between $210 \mathrm{mph}$ and $290 \mathrm{mph}$ in this sensitivity analysis. The cruise speeds are important in the TSAM Mode Choice step, because they affect the trip times, which can make the short-haul mode either more or less attractive compared to the other travel modes. The TSAM demand analysis was performed for each trip length and cruise speed combination using the same methodology previously described.

The effect of varying maximum trip length on the MPM for different cruise speeds is shown in Fig. 6 . The biggest increase in MPM occurs between 300 NM and 400 NM. For the $210 \mathrm{mph}$ cruise speed, the MPM no longer increases as the maximum trip length goes beyond $600 \mathrm{NM}$. For the $290 \mathrm{mph}$ cruise speed, the MPM continues to 
grow even beyond the $900 \mathrm{NM}$ trip length. As expected, the spread between the curves increases with increasing trip length. So, for very short trips, the trip length is a moderate factor and cruise speed is a minimal factor, in terms of MPM. As the maximum trip length is increased, cruise speed becomes more important and the incremental trip length becomes less important.

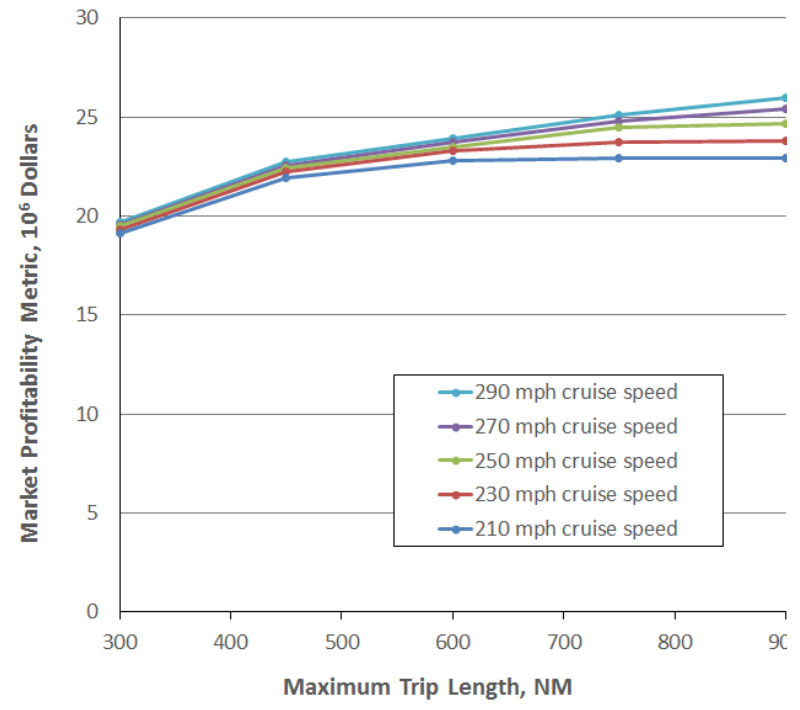

Figure 6. Sensitivity of MPM to Maximum Trip
Length for Various Cruise Speeds.

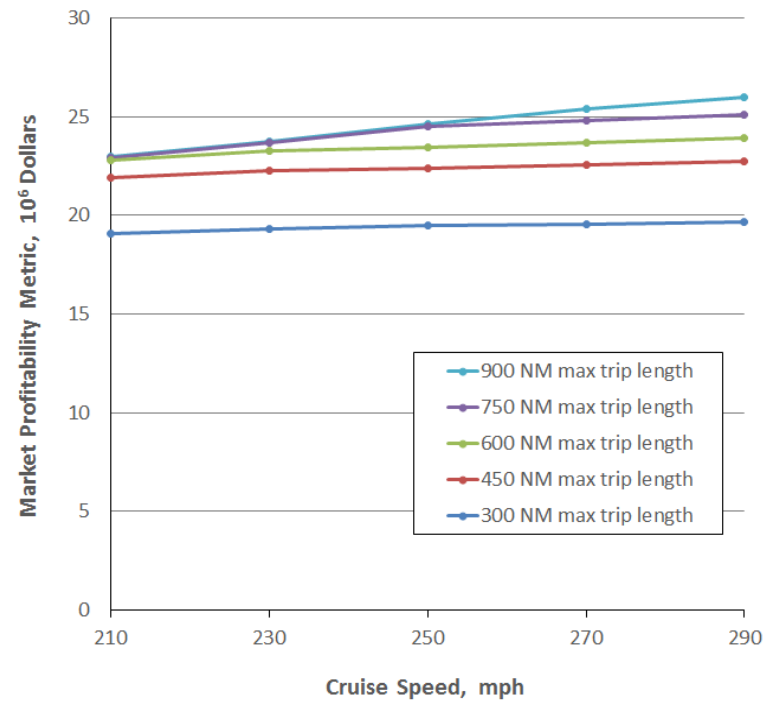

Figure 7. Sensitivity of MPM to Cruise Speed for Various Maximum Trip Lengths.

The effect of varying the cruise speed for various maximum trip lengths is shown in Fig. 7. The MPM is not very sensitive to the cruise speed for any of the trip lengths under $900 \mathrm{NM}$, although the slope of the MPM curve increases with increasing maximum trip length. As the maximum trip length is increased to above $600 \mathrm{NM}$, the demand curves begin to overlap, indicating there is little or no advantage to operating at longer trip lengths for the given speed range. The reason is there are few new markets opening up where the MPM is positive for these longer trip lengths.

The speed sensitivity results support the initial assumption of cruise speeds consistent with a turboprop, especially if the trip length will typically be less than $600 \mathrm{NM}$. There is a benefit in terms of MPM for higher cruise speeds, but it appears to be small for the short-haul market. However, that does not rule out a turbofan aircraft. The design team will consider a number of factors when selecting the propulsion system of the advanced short-haul aircraft, including cruise speed, noise, customer acceptance, and operating cost.

\section{Conclusion}

This study attempted to factor in both airline preference and mobility for the flying public when determining the target seat capacity for an advanced short-haul aircraft. Airlines consider a number of variables when choosing the aircraft size for operating in a particular market. In general, the airline wants to capture the most customer demand by providing service to many destinations with the most convenient number of daily departures. On the other hand, the airline wants to maximize profit, which means operating the fewest number of flights possible with the maximum practical load factor.

The advanced short-haul aircraft was modeled as a separate mode of travel in TSAM, which competed with commercial air and automobiles in the short-haul markets. Airfare and operating cost models were created for the short-haul mode in order to determine how many passengers would elect to take this mode and how many markets the aircraft could operate in. Several metrics were examined, including market profitability, number of annual round trips, and number of markets served. The sensitivity of these metrics to operating cost reductions was also examined.

The initial results of the seat capacity analysis pointed towards a capacity of about 70 passengers with current technology aircraft. However, when the mobility metrics and the potential operational cost reductions for the 
advanced short-haul aircraft were factored in, a seat capacity of about 50 passengers became more attractive. The design team ultimately settled on a seat capacity of 48 passengers. It is an interesting coincidence that this seat capacity is essentially the same as the regional jets that dominated the short-haul segment starting in the 1990's.

The cruise speed and trip length sensitivity analysis showed that in the speed range of interest, there was little sensitivity of MPM to changes in the cruise speed for the lower max operational ranges and moderate sensitivity to changes in cruise speed for the higher (i.e. 750 NM \& 900 NM) maximum trip lengths. The sensitivity analysis also suggests that starting at about $600 \mathrm{NM}$, there is no benefit to increasing the maximum trip length in terms of airline profitability for the lower cruise speed ranges.

\section{Acknowledgments}

Thank you to the members of the Short-Haul Revitalization Study team. This study was supported by NASA's Advanced Air Transport Technology Project.

\section{References}

1 Thomas, A., "IN FOCUS: Boom and bust, the regional jet phenomenon," FlightGlobal [Online Journal] URL: http://www.flightglobal.com/news/articles/in-focus-boom-and-bust-the-regional-jet-phenomenon-370541 [cited 6 October 2015]

2 Maxon, T., "Short Haul Flights lose favor with fliers," Los Angeles Times, 12 January 2011. URL: http://articles.latimes.com/2011/jan/12/business/la-fi-short-haul-20110112 [cited 6 October 2015].

${ }^{3}$ Wilson, B. J., "ANALYSIS: Prospects Continue to Dim for 50-Seat Regional Jets," Airways News [Online Journal] URL: http://airwaysnews.com/blog/2014/10/21/analysis-prospects-continue-to-dim-for-50-seat-regionaljets [cited 6 October 2015].

${ }^{4}$ Wittman, M. D., and Swelbar, W. S., "Trends and Market Forces Shaping Small Community Air Service in the United States," May 2013. DSpace@MIT [Online Journal] URL: http://hdl.handle.net/1721.1/78844 [cited 10 September 2016].

${ }^{5}$ Baik, H., Trani, A., Hinze, N., Swingle, H., Ashiabor, S. and Seshadri, A., "Forecasting Model for Air Taxi, Commercial Airline, and Automobile Demand in the United States," Journal of the Transportation Research Board, October 2008.

6 Woods and Poole Economics, 2014 Complete Economic and Demographic Data Source [CD-ROM], Washington D.C., 2014.

${ }^{7}$ Bureau of Transportation Statistics, U.S. Department of Transportation, “American Travel Survey: Technical Documentation", Washington D.C., 1995.

${ }^{8}$ Rama-Murthy, K., "Modeling of United States Airline Fares - Using the Official Airline Guide (OAG) and Airline Origin and Destination Survey (DB1B)", M.S. Thesis, Dept. Civil Eng., Virginia Polytechnic Institute and State University, 2006.

9 Swan, W., and Adler, N., "Aircraft trip cost parameters: A function of stage length and seat capacity," Transportation Research Part E, vol. 42, pp. 105-115, March 2006.

${ }^{10}$ National Aeronautics and Space Administration, "National Aeronautics Strategic Implementation Plan," NP2015-03-1479-HQ, Washington D.C., 2015, p. 5 